Archives de sciences sociales des religions

136 | octobre - décembre 2006

Les Archives... cinquante ans après

\title{
Roland Tournaire, Genèse de l'Occident chrétien
}

Paris, L'Harmattan, 2001, 431 p.

Jean-Daniel Dubois

\section{CpenEdition}

Journals

Édition électronique

URL : http://journals.openedition.org/assr/4083

DOI : 10.4000/assr.4083

ISSN : $1777-5825$

Éditeur

Éditions de l'EHESS

Édition imprimée

Date de publication : 1 décembre 2006

Pagination : 115-283

ISBN : 2-7132-2124-2

ISSN : 0335-5985

Référence électronique

Jean-Daniel Dubois, "Roland Tournaire, Genèse de l'Occident chrétien », Archives de sciences sociales des religions [En ligne], 136 | octobre - décembre 2006, document 136-107, mis en ligne le 14 février 2007, consulté le 21 septembre 2020. URL : http://journals.openedition.org/assr/4083 ; DOI : https:// doi.org/10.4000/assr.4083

Ce document a été généré automatiquement le 21 septembre 2020

(C) Archives de sciences sociales des religions 


\section{Roland Tournaire, Genèse de l'Occident chrétien}

Paris, L'Harmattan, 2001, 431 p.

Jean-Daniel Dubois

1 «La présentation traditionnelle des origines chrétiennes repose sur un réseau de présupposés établis au quatrième siècle. Promus en lieux communs, ils ne sont pas l'objet d'enquête ». Voilà les premiers mots qui ouvrent cette approche originale des premiers siècles du christianisme; dès la première page, on perçoit un enjeu polémique: l'auteur veut arriver à montrer que le christianisme (appelé ici le "néochristianisme») a réussi à fonder son identité sur la construction idéologique d'une organisation ecclésiastique, s'appuyant sur les structures de l'empire romain, en éliminant progressivement le christianisme « originel », ancré dans les textes bibliques vétérotestamentaires, surtout prophétiques, et illustré dans les premières années du christianisme par « la Doctrine des deux Voies » attestée dans les écrits de la Didachè ou du Pasteur d'Hermas. L'auteur connaît bien les textes anciens, mais pas la bibliographie récente sur les sujets qu'il aborde; il manifeste même un certain agacement pour les travaux historiques du début du $\mathrm{xx}^{\mathrm{e}}$ siècle ; mais traque chaque fois qu'il est possible les erreurs de traduction et les bévues historiques. Il repère ainsi des traces du christianisme qu'il prend pour originel dans les écrits, surtout latins, des premiers Pères de l'Église, en montrant à partir de textes de martyrs, d'écrits de Tertullien, de Cyprien, d'Augustin que ce christianisme persiste encore au temps des premières persécutions, celles de Dèce et de Dioclétien, jusqu'au conflit du christianisme occidental avec les donatistes en Afrique du Nord. Autrement dit, on sent au fur et à mesure des chapitres de ce livre que l'auteur valorise, à l'exception de saint Augustin, tout ce qui provient d'Afrique du Nord (voir par ex. p. 428-429 l'annexe sur les noms antiques et modernes des cités d'Afrique du Nord concernées par son étude). En revanche, il considère que ce qui vient de Rome est pernicieux alors que ce qui manifeste un semblant d'autonomie ou de résistance face au christianisme romain, voire à l'empire, est la trace du christianisme « originel » qu'il veut reconstruire. Ainsi à la page 284 par exemple, saint Augustin "n'a rien de "berbère", ni même d'Africain, contrairement à ce qui se dit souvent »; pour R. Tournaire, saint Augustin n'est que le 
suppôt d'un christianisme romanisé - en Italie, en Gaule ou en Espagne et issu des familles aristocratiques de l'Occident chrétien - qui a tenu les grandes propriétés foncières et les rênes du pouvoir politique et culturel. Il est de plus responsable d'un malentendu fondamental sur le libre-arbitre, en attribuant un péché à la chair de l'homme, et en défendant un christianisme soumis aux autorités politiques, sur la base d'une lecture de l'épître de Paul aux Romains. Saint Augustin aurait donc contribué à pervertir le christianisme originel grâce aux errements des hérétiques gnostiques et des manichéens.

D'une manière générale, certains chapitres proposent une lecture rafraîchissante de quelques grands conflits qui ont agité le christianisme antique. Avec les chapitres sur Cyprien, on comprend mieux les querelles suscitées par la présence dans les rangs des communautés chrétiennes de chrétiens ayant failli dans la persécution; dans les chapitres sur le donatisme, on appréciera la mise en valeur des conflits politiques entre le christianisme africain et le christianisme que cherche à imposer l'évêque d'Hippone, saint Augustin. R. Tournaire met en regard les points de vue adverses en présence, notamment quand il y a malentendu sur le sens des mots (cf. par ex. dans le chap. 15, les discussions sur le sens de traditores). Le concile de Carthage en 411 qui a condamné les donatistes fait aussi l'objet de nombreuses pages.

Même si selon nous, ce portrait des origines chrétiennes est trop exclusivement bâti sur des sources latines et non grecques, $R$. Tournaire fait une très belle exception avec trois chapitres (12 à 14) qui présentent l'œuvre historique d'Eusèbe de Césarée écrite en grec. Il a raison de souligner que la construction du discours historique d'Eusèbe sur les persécutions a fait croire, jusqu'à une période encore récente, que les persécutions contre le christianisme ont commencé dès le premier siècle, alors qu'on ne peut parler véritablement de persécutions qu'avec celles de Dèce et de Dioclétien, au milieu du $\mathrm{III}^{\mathrm{e}}$ siècle et au début du IV ${ }^{e}$, et sans la perspective hagiographique de l'œuvre d'Eusèbe qui cherche à gonfler les chiffres et "falsifier» les événements. Cette position de $R$. Tournaire est maintenant opinion commune depuis plusieurs dizaines d'années. En revanche, il est difficile de suivre l'auteur dans sa façon de généraliser : par ex. p. 261, la Gaule n'aurait pas connu de persécution depuis Irénée de Lyon parce que le "christianisme gaulois s'est rallié à la politique d'intégration civile de l'Église de Rome ", et c'est ce qui expliquerait, plus d'un siècle après Irénée, les bonnes relations de Constance Chlore, le père de Constantin, puis de Constantin lui-même, avec le christianisme gaulois; ou par ex. p. 215, les malheurs de l'évêque Marcel d'Ancyre déposé grâce à « la main d'Eusèbe » de Césarée. De l'histoire politique de l'arianisme et des querelles christologiques du IV siècle, l'auteur fait du christianisme un mouvement qui a infiltré les sphères du pouvoir depuis plus d'un siècle. Même si cette position a été longtemps courante dans l'historiographie chrétienne, on ne peut plus soutenir à partir de la documentation historique de l'empire romain que le passage du christianisme à l'empire s'est opéré déjà sous Constantin, comme le pense l'auteur. On ne le suivra pas non plus dans sa façon d'interpréter la persécution de l'empire contre le manichéisme en 302, et non en 297 selon R. Tournaire, p. 203 et passim, comme on le disait jusqu'il y a vingtaine d'années. Mani n'a d'ailleurs pas été crucifié (p. 203), mais il est mort dans les chaînes en prison en 276 ou en 277. Il est enfin difficile d'être convaincu par la thèse de l'auteur sur le « mauvais » penchant du christianisme à flirter avec la philosophie grecque (passim) qui expliquerait finalement l'attrait du christianisme pour la société civile de l'empire et le rejet du christianisme primitif 
d'origine juive. Au cœur de cette opposition entre ce qui est juif, selon l'auteur " israëlite » et ce qui est grec, l'auteur situe le malentendu augustinien sur le librearbitre et l'exercice de la volonté. En bonne rigueur historique, il ne suffit pas d'affirmer que saint Augustin a mal compris le christianisme originel, il faut encore démontrer que ce que dit Paul sur la volonté n'est pas du même tabac que l'argument augustinien, d'autant plus que l'auteur ignore que le libre-arbitre était déjà défendu par certains chrétiens gnostiques valentiniens $\mathrm{du} \mathrm{II}^{\mathrm{e}}$ siècle, bien avant Irénée de Lyon, considéré souvent comme l'un des champions de la liberté chrétienne. Ce livre est sans doute à déconseiller aux admirateurs de l'œuvre historique de P. Monceaux sur le christianisme latin; il plaira plutôt à ceux qui n'aiment pas les idées reçues. Il faut peut-être le lire si l'on aime l'histoire du christianisme en Afrique du Nord, ou si l'on veut faire l'histoire des chrétiens "debout et non couchés »; mais il manque souvent d'arguments solides pour convaincre. 